\title{
Identification of a Location at Chromosome 19p in a Big Chinese Family with Charcot-Marie-Tooth Disease
}

\author{
Fei-Feng Li ${ }^{1}$, Xu-dong Wang ${ }^{2}$, Min-wei Zhu ${ }^{3}$, Hui-wen Xiao ${ }^{1}$, Quan Yang ${ }^{1}$ Xin Shao ${ }^{4}$, Hong-lin Feng ${ }^{2 *}$, Zhi-Guo Lin ${ }^{3 *}$ and Shu-Lin Liu ${ }^{1,5,6 *}$
}

${ }^{1}$ Genomics Research Center, Harbin Medical University, China

${ }^{2}$ Department of Neurology, The First Affiliated Hospital, Harbin Medical University, China

${ }^{3}$ Department of Neurosurgery, The First Affiliated Hospital, Harbin Medical University, China

${ }^{4}$ Department of Colorectal Surgery, the Second Affiliated Hospital of Harbin Medical University, China

${ }^{5}$ Genetic Detection Center of the First Clinical College, Harbin Medical University, China

${ }^{6}$ Department of Microbiology and Infectious Diseases, University of Calgary, Calgary, Canada

\begin{abstract}
Background: Autosomal dominant Charcot Marie Tooth disease (CMT) diseases is an inherited peripheral neuropathies disease, the prevalence is $17-40$ per 100,000 individuals $17-40$ per 100,000 individuals. The complex genetic mode and large number of CMT causing genes and loci made it is very hard for clinicians and researchers when trying to determine the underlying genetic diagnosis. In this work, we want to identify the cause for a Chinese family with Charcot-Marie-Tooth disease.

Methods: Family history data were recorded. Clinical and Electromyography examinations were performed on the ten affected and ten unaffected family members. All the members were genotyped with microsatellite markers at loci considered to be associated with CMT. Two-point LOD scores were calculated using the Linkage software after genotyping. Some highly suspect genes were excluded by direct sequencing.

Results and Conclusions: The clinical and pathological features were relatively gently, but which became gradually worse, with the increased genetic generation, and the onset age of the affected members. Linkage analysis was obtained at markers D19S433 (LOD score $[Z]=2.03$, recombination fraction $[\theta]=0.0)$ and D19S916 $(Z=1.6$, $\theta=0.0)$. Sequencing the dynamin 2 gene $(D N M 2)$ didn't found any variation in the translated region. There may be some other gene or loci associated with this disease.
\end{abstract}

Keywords: CMT; Linkage analysis; Gene mutation; DNM2; MNCV

\section{Introduction}

Charcot-Marie-Tooth (CMT) disease is a genetically and clinically heterogeneous inherited disease, affecting peripheral neuropathies $[1,2]$. The prevalence of the disease is $17-40$ per 100,000 people [3]. So far, more than 40 genes and 900 loci have been identified for their association with the disease (http://www.molgen.ua.ac.be/ CMTMutations/Mutations/MutByGene.cfm). The hereditary modes of CMT include Autosomal Dominant (AD) demyelinating (CMT1), $\mathrm{AD}$ axonal (CMT2), autosomal recessive and X-linked (CMTX) forms. The highly complex genetic modes and extraordinary large number of loci to cause CMT make it difficult for clinicians and researchers to determine the actual underlying genetic etiology. CMT is also known as hereditary motor and sensory neuropathy (HMSN), because it also affects the motor and sensory nerves. Variable ages of onset and progressive distal muscle weakness and atrophy are the main clinical characteristics, usually starting from the lower limbs and subsequently affecting the upper extremities [4]. The most typical features of the disease are gradual atrophy of distal muscles of the feet and legs, and the thin legs have been likened to an "inverted champagne bottle".

Point mutations and sequence deletions in the dynamin 2 (DNM2) genes have been associated with the CMT disease. In 2005, the DNM2 gene was first reported to be associated with CMT [5]. Since then, three point mutations and two sequence deletions in the DNM2 gene have been described in DNM2 related CMT disease [5,6]. But the full spectrum of genetic changes leading to this disease is yet unknown. Here, we report a 4-generational Han Chinese family with CMT; we located the responsible locus at chromosome 19p13.2-19q12, which is flanked by markers D19S433 and D19S916.

\section{Materials and Methods}

\section{Affected and unaffected individuals in the family}

We ascertained a 4-generational Chinese Han family with nonsyndromic CMT (Figure 1) at the First Affiliated Hospital of Harbin Medical University, Harbin, China. Informed consent was obtained from each participant, consistent with the Declaration of Helsinki. We recorded their medical history in detail. Physical and electromyography examination was carried out on each of the family members. Genomic DNA was extracted from peripheral blood leukocytes using standard protocols.

\section{Genotyping}

Polymerase Chain Reactions (PCRs) were carried out with microsatellite markers close to candidate loci associated with autosomal

*Corresponding authors: Hong-ling Feng, Department of Neurology,
The First Affiliated Hospital, Harbin Medical University, China, E-mail: fenghonglin5678@sina.com

Zhi-Guo Lin, Department of Neurosurgery, The First Affiliated Hospital, Harbin Medical University, China, E-mail: linzhiguo@sohu.com

Shu-Lin Liu, Genomics Research Center, Harbin Medical University, China, E-mail: slliu@ucalgary.ca

Received June 12, 2013; Accepted July 25, 2013; Published July 27, 2013

Citation: Li FF, Wang X, Zhu M, Xiao H, Yang Q, et al. (2013) Identification of a Location at Chromosome 19p in a Big Chinese Family with Charcot-Marie-Tooth Disease. J Mol Biomark Diagn 4: 144. doi:10.4172/2155-9929.1000144

Copyright: (c) 2013 Li FF, et al. This is an open-access article distributed under the terms of the Creative Commons Attribution License, which permits unrestricted use, distribution, and reproduction in any medium, provided the original author and source are credited 
dominant CMT. PCR products from each DNA sample were separated on a $6 \%$ polyacrylamide gel and analyzed. Pedigree and haplotype data were managed using Cyrillic (version 2.1) software. Exclusion analysis was performed by allele sharing in affected individuals.

\section{Linkage analysis}

A two-point linkage was calculated with the LINKAGE (version 5.1) package. Autosomal dominant CMT was analyzed with full penetrance and a gene frequency of 0.001 . Allele frequencies for the markers were assumed to be equal in both genders. The marker order and distances between the markers were taken from the NCBI (http:// www.ncbi.nlm.nib.gov) databases.

DNA sequencing: Individual introns and exons of DNM2 were amplified by PCR using primer pairs shown in Table 1. The PCR products were sequenced on an ABI3130 Automated Sequencer.

\section{Results}

\section{Clinical data}

The proband was a 38-year-old male (III: 24; Figure 1), who had difficulties in walking and frequently tripped starting at the age of 4. Gradually, the other clinical manifestations were also observed, including loss of muscle bulk in the lower limbs, inability to lift feet, hollow feet and sensory loss in the feet (Figure 2). At the age of 30, he started experiencing mild weakness and muscle atrophy in the hands, resulting in problems with fine motor skills. Neurological examination showed reduced biceps and triceps reflexes, and patellar and plantar reflexes were absent. The touch and vibration sensations of distal lower extremities were lost. Finger-to-nose and heel-to-shin tests were normal. There was no disturbance of autonomic function. Nerve conduction studies showed that motor nerve conduction velocities were reduced, amplitudes were decreased, and distal latencies were prolonged. Median motor nerve conduction was $12.7 \mathrm{~m} / \mathrm{s}$. The Compound Motor Action Potential (CMAP) of the bilateral tibial nerves could not be elicited. Sensory nerve conduction velocities were slightly reduced. Median sensory nerve conduction was 32.2 $\mathrm{m} / \mathrm{s}$. Electromyography studies showed an increase in duration and amplitude of action potentials in the right tibia is anterior muscle.

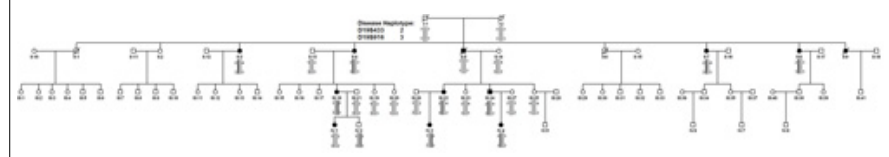

Figure 1: Pedigree and haplotype of the CMT family. Four-generation pedigree segregating autosomal dominant Charcot Marie Tooth disease. Haplotyping shows segregation of two microsatellite markers on 19p. Squares and circles indicate males and females, respectively. Filled symbols and bars denote affected status.

\begin{tabular}{lll}
\hline Gene (Exon) & Forward primers $\left(\mathbf{5}^{\prime} \rightarrow \mathbf{3}^{\prime}\right)$ & Reverse primers $\left(\mathbf{5}^{\prime} \rightarrow \mathbf{3}^{\prime}\right)$ \\
\hline DNM2 (1) & TCTCCCAGCCTGAAACC & TGCCACTCACCTCCTCATC \\
DNM2 (2) & CAGCGACCAGCATTGAGA & CCCTGGCATTTGCTATTT \\
DNM2 (3) & AGGTGAAGCTGGGTTGG & CCGTGAGGGAACTTTCTGG \\
DNM2 (Intron) & CCCGCAGAACGTCTACAA & CCACCTCAGCCTCCCAAA \\
DNM2 (4) & TTCCAATGCCCAGGTGAG & CTACCGTGCCCGGCTAAT \\
DNM2 (5) & GTTCTGGGTTGGGGTAT & GGCGGGGTATTTATTCACA \\
DNM2 (6) & GCAAGGGAAGGTGGACTG AGGGCTCCGCTACTCTGTG \\
DNM2 (7) & GGGCTCACTGAGGGTCAAA & GGATGGTGTCAAGGGTTCTGG \\
DNM2 (7b) & GGGGTGTTGCACTTTGGG & ATGGCCGGGAAGGACTAT \\
\hline
\end{tabular}

Table1: PCR primers for DNM2 sequence analysis.

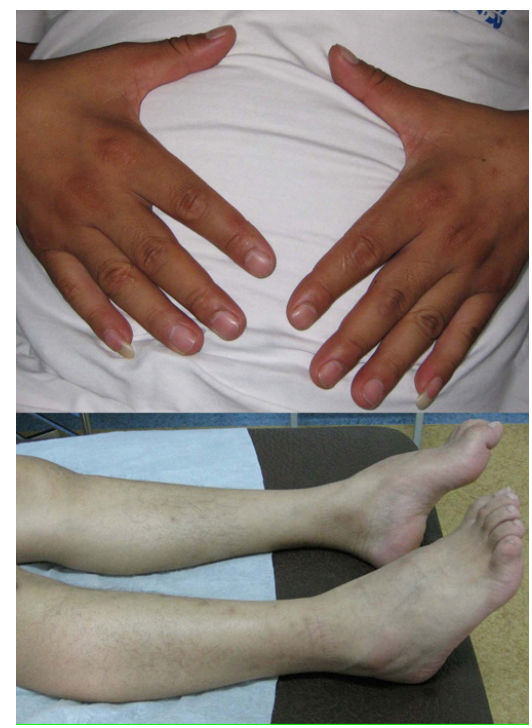

Figure 2: The photographs of the affected individual $\square$ : 24 , show that the proband had hollow foot and loss of muscle bulk in the lower limbs.

This four-generational family included 12 affected individuals with congenital CMT. Their complete blood count, liver and kidney function tests, creatine kinase, myoglobin, blood lipid and glucose levels, and routine urinalysis were all normal (Figure 1).There was no history of other nervous or systemic abnormalities in the family.

\section{Linkage and haplotype analysis}

All the candidate genes were examined by allele sharing and linkage analysis or direct sequencing. Linkage was found with markers D19S433 and D19S916, and the maximum LOD score was 2.03 (at $\theta=0$ ). Haplotype analysis showed that the responsible locus was localized at chromosome 19p13.2-19q12, flanked by markers D19S433 and D19S916 (Figure 1 and Table 2).

\section{Mutation analysis for DNM2}

Direct cycle sequencing of the amplified fragments of DNM2 in all affected individuals did not reveal any variation in the translated region. We also analyzed additional genes with direct gene sequencing, including PMP22 (CMT1A and CMT1E), MPZ (CMT1B), LITAF (CMT1C), EGR2 (CMT1D) and YARS (DI-CMTC), but we did not find any variation in the translated regions of those genes either.

\section{Discussion}

The phenotypes of CMT disease vary greatly according to the families and pathogenic genes. The clinical features can range from severe muscle atrophy, sensory loss to no symptoms in affected members [7-9]. Notably, in the patients, the clinical symptoms became gradually worse and the onset age of the affected members were advanced with the increased genetic generation (Table 3 ). The clinical features of the second generation affected members were mainly the loss of deep tendon reflexes and sensation of distal extremities (II : $5,7,13,15)$; the third generation affected members were more serious, one affected (III: 21) showed absence of patellar reflexes and loss of the pain sensation of distal extremities; the clinical features of the proband (III:24) were more serious (Table 3).

The clinical and pathological features of CMT include approximately 88\% CMT1A patients have slow Motor Nerve Conduction Velocities 
Citation: Li FF, Wang X, Zhu M, Xiao H, Yang Q, et al. (2013) Identification of a Location at Chromosome 19p in a Big Chinese Family with CharcotMarie-Tooth Disease. J Mol Biomark Diagn 4: 144. doi:10.4172/2155-9929.1000144

\begin{tabular}{llllllllll}
\hline \multirow{2}{*}{ Marker } & & \multicolumn{8}{c}{ LOD scores by recombination fraction $(\boldsymbol{\theta})$} \\
& $\mathbf{0}$ & $\mathbf{0 . 0 4}$ & $\mathbf{0 . 0 9}$ & $\mathbf{0 . 1 4}$ & $\mathbf{0 . 1 9}$ & $\mathbf{0 . 2 4}$ & $\mathbf{0 . 2 9}$ \\
\hline D19S433 & 2.03 & 1.85 & 1.61 & 1.38 & 1.15 & 0.93 & 0.71 \\
D19S916 & 1.60 & 1.51 & 1.38 & 1.25 & 1.11 & 0.96 & 0.80 \\
\hline
\end{tabular}

Note: The highest observed LOD score was $2.03(\theta=0)$ for marker D19S433

Table2: Two Point LOD scores for linkage between disease locus and markers on chromosome 19

\begin{tabular}{|c|c|c|c|}
\hline Patient & Sex & Onset age & Physical examination \\
\hline II : 3 & M & 53 & $\begin{array}{l}\text { Deep tendon reflexes and sensation of distal } \\
\text { extremities were lost. }\end{array}$ \\
\hline II $: 4$ & M & 50 & $\begin{array}{l}\text { Deep tendon reflexes and sensation of distal } \\
\text { extremities were lost. }\end{array}$ \\
\hline II : 5 & $F$ & 50 & Death \\
\hline II : 7 & M & 59 & $\begin{array}{l}\text { Deep tendon reflexes and sensation of distal } \\
\text { extremities were lost. }\end{array}$ \\
\hline II : 8 & M & 59 & $\begin{array}{l}\text { Deep tendon reflexes and sensation of distal } \\
\text { extremities were lost. }\end{array}$ \\
\hline II : 9 & M & 49 & Death \\
\hline III: 18 & M & 8 & $\begin{array}{l}\text { Deep tendon reflexes and sensation of distal } \\
\text { extremities were lost. }\end{array}$ \\
\hline III: 22 & M & 5 & $\begin{array}{l}\text { Patellar reflexes were absent; the pain sensation of } \\
\text { distal extremities was lost. }\end{array}$ \\
\hline III: 24 & $F$ & 4 & $\begin{array}{l}\text { Biceps and triceps reflexes reduced, patellar and } \\
\text { plantar reflexes were absent; the touch and vibratory } \\
\text { sense of lower distal extremities were disappeared. }\end{array}$ \\
\hline IV: 1 & M & 15 & $\begin{array}{l}\text { Deep tendon reflexes and sensation of distal } \\
\text { extremities were lost. }\end{array}$ \\
\hline IV: 3 & M & 2 & $\begin{array}{l}\text { Deep tendon reflexes of lower distal extremities were } \\
\text { reduced. }\end{array}$ \\
\hline IV: 4 & M & 1.5 & $\begin{array}{l}\text { Deep tendon reflexes of distal extremities were } \\
\text { absent; the touch and vibratory sensation were } \\
\text { disappeared at the lower legs. }\end{array}$ \\
\hline
\end{tabular}

Table 3: Clinical features of the affected individuals

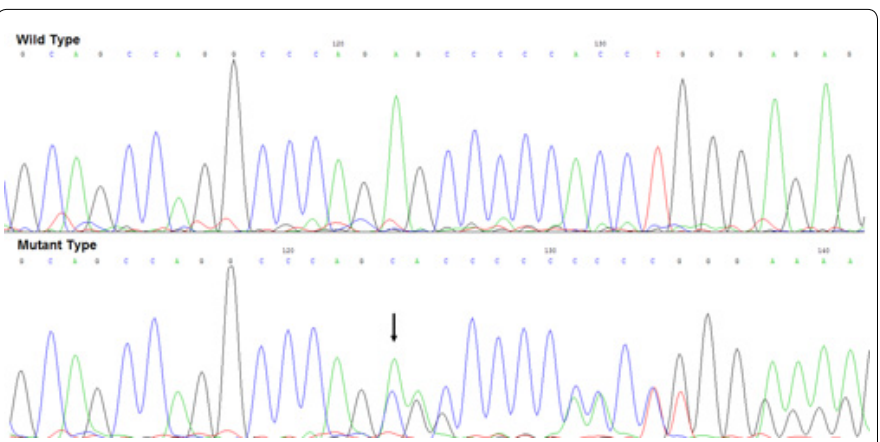

Figure 3: DNA sequence chromatograms of the DNM2 gene. DNA sequence chromatograms of the c. C insertion, between the exon 3 and exon 4 of the DNM2 gene. The remainder of the coding sequence showed no other change.

(MNCV) in the upper extremities. 52.8\% CMT1X and 27.8\% CMT1B patients have intermediate MNCV. And some patients with very slow MNCV and delayed walking were very likely to have CMT1A (68\%) or CMT1B (32\%). Patients with CMT1B unlikely to have very slow MNCV walked before 15 months of age, and patients with CMT2A very likely axonal forms of CMT [8]. Three types of dominantly inherited CMT with intermediate MNCV had been identified. CMTDI2 was linked to chromosome 10q24.1-q25.1[10-12], DI-CMTC was linked to chromosome 1p34-p35 [13], and DI-CMTB was linked to chromosome 19p12-13.2 [14,15]. Mutations had been identified in DNM2 gene for DI-CMTB [5]. From the previous researches, DNM2 mutations in DICMTB mainly located in its PH domain $[5,6,16,17]$.
Because nerve conduction studies of the family showed that Motor Nerve Conduction Velocities (MNCV) were reduced, amplitudes were decreased, and distal latencies were prolonged. Median motor nerve conduction was $12.7 \mathrm{~m} / \mathrm{s}$. Sensory nerve conduction velocities were slightly reduced. Median sensory nerve conduction was $32.2 \mathrm{~m} / \mathrm{s}$. Therefore, we also focus on the seven genes by direct gene sequencing, since the genetic changes of these genes may lead to the same clinical phenotype.

Although significant linkage was found with markers D19S433 and D19S916, and haplotype analysis showed that the responsible locus was localized at chromosome 19p13.2-19q12. The DNM2 gene was loci in this region. By direct gene sequencing, we didn't found any variation in the translated region of the DNM2 gene. But we found a "C" insertion in the DNM2 gene intron between the exon 3 and 4 , in four affected family members (III:22, III:24, IV:3 and IV:4), the other affected or normal family members did not have the insertion (Figure 3). DNM2 mutations can also be identified in DNM2-CNM patients $[9,18-20]$. The clinical and pathological features of DNM2-CNM were plantar muscle, calf and posterior atrophy [20], cardiac or respiratory failure, ptosis or ophthalmoplegia [18]. None of the patients in this family showed any abnormality in muscle, cardiac, respiratory or ocular. We also excluded the other genes, which had been identified linked with the CMT diseases, by allele sharing.

\section{Linkage analysis}

In conclusion, we described a four generation Chinese family with CMT disease. The clinical and pathological features were relatively gently, but which became gradually worse, with the increased genetic generation, and the onset age of the affected members also advanced. We also excluded all the genes, which had been identified, linked with the CMT diseases, by allele sharing and direct gene sequencing. Maybe there are some other genes or loci, associated with this disease.

\section{Acknowledgements}

The authors thank the patients and the family members for their cooperation and participation in this study. This work was supported by a grant from Harbin Medical University (2012081), grants of National Natural Science Foundation of China (NSFC30870098, 30970119, 81030029), and a Specialized Research Fund for the Doctoral Program of Higher Education (No.20092307110001) to SLL.

\section{References}

1. Charcot J MP (1886) Sur une forme particulière d'atrophie musculaire progressive, souvent familiale débutant par les pieds et les jambes et atteignant plus tard les mains. Revue médicale, Paris 6: 97-138.

2. Tooth $H$ (1886) The peroneal type of progressive muscular atrophy Dissertation, London H K Lewis.

3. Barisic N, Claeys KG, Sirotkovic-Skerlev M, Lofgren A, Nelis E, et al. (2008) Charcot-Marie-Tooth disease: a clinico-genetic confrontation. Ann Hum Genet 72: 416-441.

4. Nicolaou P, Zamba-Papanicolaou E, Koutsou P, Kleopa KA, Georghiou A, et al. (2010) Charcot-Marie-Tooth disease in Cyprus: epidemiological, clinical and genetic characteristics. Neuroepidemiology 35: 171-177.

5. Zuchner S, Noureddine M, Kennerson M, Verhoeven K, Claeys K, et al. (2005) Mutations in the pleckstrin homology domain of dynamin 2 cause dominan intermediate Charcot-Marie-Tooth disease. Nat Genet 37: 289-294.

6. Fabrizi GM, Ferrarini M, Cavallaro T, Cabrini I, Cerini R, et al. (2007) Two nove mutations in dynamin-2 cause axonal Charcot-Marie-Tooth disease. Neurology 69: 291-295.

7. Wang YW, Han WT, Jiang M, Lu CX, Li XF, et al. (2012) A novel mutation of the MFN2 gene in a Chinese family with Charcot-Marie-Tooth disease. Genet Mol Res 11: 1454-1459. 
Citation: Li FF, Wang X, Zhu M, Xiao H, Yang Q, et al. (2013) Identification of a Location at Chromosome 19p in a Big Chinese Family with CharcotMarie-Tooth Disease. J Mol Biomark Diagn 4: 144. doi:10.4172/2155-9929.1000144

Page 4 of 4

8. Miller LJ, Saporta AS, Sottile SL, Siskind CE, Feely SM, et al. (2011) Strategy for genetic testing in Charcot-Marie-disease. Acta Myol 30: 109-116.

9. Jordanova A, Irobi J, Thomas FP, Van Dijck P, Meerschaert K, et al. (2006) Disrupted function and axonal distribution of mutant tyrosyl-tRNA synthetase in dominant intermediate Charcot-Marie-Tooth neuropathy. Nat Genet 38: 197202

10. Rossi A, Paradiso C, Cioni R, Rizzuto N, Guazzi G (1985) Charcot-Marie-Tooth disease: study of a large kinship with an intermediate form. J Neurol 232: 91-98.

11. Verhoeven K, Villanova M, Rossi A, Malandrini A, De Jonghe $P$, et al. (2001) Localization of the gene for the intermediate form of Charcot-Marie-Tooth to chromosome 10q24.1-q25.1. Am J Hum Genet 69: 889-894.

12. Villanova M, Timmerman $V$, De Jonghe $P$, Malandrini A, Rizzuto N, et al. (1998) Charcot-Marie-Tooth disease: an intermediate form. Neuromuscul Disord 8: 392-393.

13. Jordanova A, Thomas FP, Guergueltcheva V, Tournev I, Gondim FA, et al. (2003) Dominant intermediate Charcot-Marie-Tooth type C maps to chromosome 1p34-p35. Am J Hum Genet 73: 1423-1430.

14. Kennerson ML, Zhu D, Gardner RJ, Storey E, Merory J, et al. (2001) Dominant intermediate Charcot-Marie-Tooth neuropathy maps to chromosome 19p12-p13.2. Am J Hum Genet 69: 883-888.
15. Zhu D, Kennerson M, Merory J, Chrast R, Verheijen M, et al. (2003) Refined localization of dominant intermediate Charcot-Marie-Tooth neuropathy and exclusion of seven known candidate genes in the region. Neurogenetics 4 179-183.

16. Claeys KG, Zuchner S, Kennerson M, Berciano J, Garcia A, et al. (2009) Phenotypic spectrum of dynamin 2 mutations in Charcot-Marie-Tooth neuropathy. Brain 132: 1741-1752.

17. Bitoun M, Stojkovic T, Prudhon B, Maurage CA, Latour P, et al. (2008) A nove mutation in the dynamin 2 gene in a Charcot-Marie-Tooth type 2 patient: clinical and pathological findings. Neuromuscul Disord 18: 334-338.

18. Fischer D, Herasse M, Bitoun M, Barragan-Campos HM, Chiras J, et al. (2006) Characterization of the muscle involvement in dynamin 2-related centronuclear myopathy. Brain 129: 1463-1469.

19. Jeub M, Bitoun M, Guicheney P, Kappes-Horn K, Strach K, et al. (2008) Dynamin 2-related centronuclear myopathy: clinical, histological and genetic aspects of further patients and review of the literature. Clin Neuropathol 27 : 430-438.

20. Mori-Yoshimura M, Okuma A, Oya Y, Fujimura-Kiyono C, Nakajima H, et al (2012) Clinicopathological features of centronuclear myopathy in Japanese populations harboring mutations in dynamin 2. Clin Neurol Neurosurg 114 678-683. 